Volume 6, Issue 1 (2021), pp. 12-23

Journal of School Administration Research and Development

ISSN: 2470-8496 Print/ ISSN: 2470-850X Online

ojed.org/jsard

\title{
Principal Effects on Academic Progress Over Time and the Potential Effects of School Context and Principal Leadership Practices
}

\author{
Stephen B. Bluestein \\ Ivy Bound Academy Charter Schools, USA \\ Pete Goldschmidt \\ California State University, Northridge, USA
}

\begin{abstract}
We used interrupted time series to examine the causal effect of principals on school performance over time and whether the trajectory of performance is affected by school context and leadership practices. Results were based on a unique dataset that links responses from the National Schools and Staffing Survey with 10 years of California Academic Performance Index (API) data. These data and methods address a need identified in the literature to examine the effects of principals with more rigorous research designs. Results indicated that improved academic performance does not occur immediately but accrues over time. We estimated both the first-year impact of a principal and the subsequent impact over time. The effect size increased from 0.04 in the first year to 0.21 by year three. Exploratory analyses showed that school context and leadership practices account for a substantial portion of the variation in progress among schools: $25 \%$ and $40 \%$, for context and practices, respectively. Although the Schools and Staffing Survey afforded an opportunity to examine teacher and principal responses to academic performance over time, continued study is warranted to systematically and more concretely identify specific leadership practices that impact academic progress over time.
\end{abstract}

Keywords: interrupted time series, principal leadership practices, principal effects, SASS, schools and staffing survey, school accountability

The importance of leadership in schools is generally accepted and has been discussed extensively in the literature. Individual studies (Branch et al., 2012; Coelli \& Green, 2012; Miller, 2013) as well as meta-analyses (Liebowitz \& Porter, 2019; Robinson et al, 2008) demonstrate significant effects attributable to principals. Recent studies also continue to examine and identify specific principal leadership practices that can impact school outcomes (Day et al., 2016; Dhuey \& Smith, 2018; Dutta \& Sahney, 2016; Grissom et al., 2013; Grissom \& Loeb, 2011; Nir \& Hameiri, 2014). The expectations of a principal are well summarized by Bottoms and O'Neill (2001) who noted that school leaders were "expected to perform in the role of 'chief learning officer,' with ultimate responsibility for the success or failure of the [educational] enterprise" (p. 5). In fact, research on principal effects considers various outcomes such as academic achievement, teacher support, and school organization (Liebowitz \& Porter, 2019). Although research on principal effects is extensive, much of it is correlational or observational (Liebowitz \& Porter, 2019) and few studies examine elementary school principals explicitly. We meaningfully contribute to this line of research by utilizing a rigorous methodology to identify principal effects. Given the infeasibility of randomization, the strongest identification strategy is based on principal transitions from one school to another (Austin et al., 2019; Branch et al., 2012; Liebowitz \& Porter, 2019; Miller, 2013). We utilize a rigorous Interrupted Time Series (ITS) design to estimate the impact of principals on student academic progress. Our aim is to empirically answer three related research questions: one, does a school principal impact the trend in school achievement; two, to what extent does school context affect the trend in school achievement; and three, do principal leadership practices impact the trend in school achievement? To capture achievement trends, we use a high- 
stakes composite accountability indicator amenable to measuring progress in math and language arts. The California Academic Performance Index (API) has given way to new accountability indicators under ESSA, but is representative of a meaningful measure designed to inform school decisions. Principal leadership practices are measured by teacher and principal responses on the School and Staffing Survey (SASS), which we link to California schools because California had a consistently measured outcome (API), that is a key assumption of ITS.

\section{LITERATURE REVIEW}

Many researchers have discussed the principalship in terms of leadership skills. As far back as 30 years ago, Duke (1987) described the effectiveness of the principal as the leadership skills he or she exhibits in a variety of situations encountered on a daily basis. These encounters constitute the experiences of the principal that allow him or her to meet the needs of the school by promoting and utilizing sound educational practices, thus increasing student achievement. In fact, recent research indicates that school improvement is not solely the result of principal leadership practices but also the ability to understand and diagnose school needs and act upon those needs (Day et al., 2016). Although principal ability to effectively diagnose needs is important, it is, nonetheless, important to understand specific facets of principal behavior and practices that affect school outcomes so that these facets may be improved. Much research has addressed effective principals in relation to their behaviors (Dhuey \& Smith, 2018; Grissom, et al., 2013; Grissom \& Loeb, 2011; Nir \& Hameiri, 2014). An organizing frame is used to categorize principal behaviors into five categories (Liebowitz \& Porter, 2019; Grissom \& Loeb, 2011): 1) instructional management, 2) internal relations, 3) organizational management, 4) administration, and 5) external relations. Often the focus is on instructional and transformational leadership (Day, et al., 2016; Dutta \& Sahney, 2016; Nir \& Hameiri, 2014). The results are equivocal as some find that the extent to which principals utilize instructional leadership is the most critical factor in creating an effective school (Burch \& Spillane, 2003), while others find that other factors may be equally if not more important (Liebowitz \& Porter, 2019). Also, Horng, et al. (2010) find a significant and positive relationship between spending time on organization management tasks such as hiring staff and allocating budgets.

Over three decades ago, Blank (1986) studied the practices of 32 urban high school principals to identify common behaviors and activities drawn from principal and teacher interviews. These practices center on transformational and instructional leadership. Much research since has focused on identifying specific leadership practices that are most strongly associated with positive outcomes. Instructional leadership largely focuses on the principal's role in framing the school's mission, coordinating and monitoring the school's instructional program, and developing a positive learning culture (Hallinger \& Murphy, 1985; Mangin, 2007). In contrast, transformational leadership (Bass, 1998; Stein \& Nelson, 2003) emphasizes collaboration with stakeholder groups, with particular emphasis on the role of the principal in inspiring and motivating the staff, developing commitment to a common vision, building the staff's capacity to work collaboratively, and shaping the organizational culture.

An emphasis on the teaching and learning aspects of school leadership is characteristic of the instructional leadership literature. This literature generally indicates that a strong, directive principal, focused on curriculum and instruction, results in positive school outcomes. The literature reveals that principals make a difference in student learning (Day, et al., 2016; Dutta \& Sahney, 2016; Knuth \& Banks, 2006; Liebowitz \& Porter, 2019; Marzano et al., 2005; Owings, et al., 2006; Waters \& Kingston, 2005).

Several meta-analyses examining the impact of principals on various outcomes and on the relationship between leadership practices and student outcomes have also been conducted (Abu-Hussain, 2014; Cotton, 2003; Liebowitz \& Porter, 2019; Waters et al., 2003). Results of these meta-analyses find that effect sizes vary but generally range from approximately 0.05 to 0.33 , with the most recent analysis reporting a maximum effect size for academic outcomes of 0.16 (Liebowitz \& Porter, 2019).

Complementing these meta-analyses, some researchers have focused on the principal as manager and have attempted to identify specific behaviors associated with improved school performance beyond leadership practices (Dhuey \& Smith, 2018; Grissom et al., 2013). Results indicate that specific behaviors, particularly teacher evaluation and coaching, have positive effects on year-to-year gains in academic progress. Effective leadership addresses recruitment and motivation of quality teachers' (Harris et al., 2006; Jacob \& Lefgren, 2005) engagement and development of teachers (Marks \& Printy, 2003; Mulford \& Silins, 2003) and staff motivation, commitment, and empowerment (Dvir et al., 2002). Such leadership practices also benefit the organization as a whole by fostering shared purposes and goals, promoting a collaborative organizational culture, and using networks to leverage improvement efforts (Mulford \& Silins, 2003). 
The extant literature on principals' impact on school outcomes is extensive and consistently finds that principal contributions to the school are substantively important. Three important results are relevant for this study: one, principals can diagnose and respond to school issues (Day, et al., 2016) and that school outcomes generally improve with experience (Miller, 2013); two, principal effects have been classified into several categories, and those developed by Grissom and Loeb (2011) provide a guide as what to consider in terms of behaviors and practices; and three, the impact of principals has overwhelmingly been estimated as an effect on school outcomes but not as an effect on school progress.

\section{DATA AND METHODS}

We used the 2007-2008 restricted-use SASS, which is the last SASS that allowed us to collect both pre- and post-survey school outcomes data amenable to analyses examining the impact of principals. The SASS ${ }^{1}$ is conducted by the United States Department of Education's National Center for Education Statistics (NCES) to collect extensive data on public, public charter, Bureau of Indian Affairs (BIA) funded, and private schools in the United States ${ }^{2}$ (Tourkin, et al., 2007). We examined regular, full-time, public school elementary teachers and principals. We merged the 2007-2008 SASS and the 2008-2009 follow-up SASS restricted use teacher and principal survey results to the Common Core of Data (CCD) and California Academic Performance Index (API) data. Using the CCD to link the SASS to California API data (1999 through 2008) has previously been utilized by Tickle et al $\left(2010^{3}\right)$. This resulted in a final analysis sample of 166 California elementary school principals. The API average ranges from 635 in 1999 to 772 in 2008 . The average standard deviation is approximately 105.

School accountability has changed since 2007 and No Child Left Behind (NCLB), and there is increasing acceptance that school performance is not solely reflected in assessment results, but assessment results continue to form a substantively meaningful component of school success under Every Student Succeeds Act (ESSA). The API, which in California was a composite of state assessment results for schools, was used as an accountability indicator from 1999 through 2014. The API assigns one number to a school on a scale of 200 to 1,000, with a score of at least 800 as the goal. Importantly, the API meets the What Works Clearinghouse (WWC) criteria for an outcome when using interrupted time series (Kratochwill et al., 2010).

Based on the literature, we formed principal leadership constructs using both teacher and principal variables from the SASS. Constructs reflect the categorization developed by Grissom \& Loeb (2011), most recently applied by Liebowitz \& Porter (2019) and also reflecting transformational and instructional leadership practices (Day, et al., 2016; Dutta \& Sahney, 2016). The constructs we developed for this study are based on equally weighted composites ${ }^{4}$. Reliability for each of the constructs is presented in Table 1 and range from about 0.4 to 0.8 . The constructs in Table 1 reflect the following: teacher control is generally related to teachers' control of instructional practices; principal support of teachers represents the extent to which a principal is supportive of and communicates goals to teachers; principal support of first-year teacher reflects principal practices such as providing feedback and support with aides; principal influence on instruction reflects principal influence on curriculum and training for teachers; parent involvement represents percentage of students whose parents attend various school functions and volunteering activities; principal facilitating parent involvement represents principal facilitation of parent support, such as parent lounges and dedicated staff; and principal autonomy represents principal autonomy in teacher evaluations, hiring, and budget decisions. Full principal autonomy dichotomizes principal autonomy into principals who endorsed the highest autonomy response to all items in composite versus all others.

Table 1 also presents descriptive statistics for the variables we used in the analyses. Importantly, the sample consisted of schools that had on average between two pre-principal change occasions and seven post-principal change occasions. Hence, we conducted analyses on both the full sample and a subsample of schools that met the recommended three pre and three post (Bloom, 2003) occasions. We refer to this subsample as the $3+3$ Sample.

Figure 1 below summarizes the trend in API for the sampled schools and all California elementary schools and indicates that the two trends are virtually identical and, the dotted lines imply, API growth over this period was increasing but decelerating.

\footnotetext{
${ }^{1}$ After 2010 the SASS was renamed to the National Teacher and Principal Survey (NTPS).

${ }^{2}$ More detail about SASS is available at: https://nces.ed.gov/surveys/sass/.

${ }^{3}$ See Tickle, Chang, and Kim (2010) for detailed steps in linking these data.

${ }^{4}$ The specific items for each construct are available from the authors.
} 
Table 1

Descriptive Statistics for School Context, Teacher Perceptions, and Principal Leadership

\begin{tabular}{lccccc}
\hline \multicolumn{1}{c}{ School Context } & Min & Max & $M$ & $S D$ & Reliability \\
\hline Students Eligible for NSLP (\%) & 0.00 & 100.00 & 57.03 & 33.12 & \\
Students with IEP (\%) & 0.00 & 93.75 & 12.60 & 14.60 & \\
Students who are EL (\%) & 0.00 & 100.00 & 30.39 & 26.72 & \\
Principal Practices - Teacher Perceptions & & & & & \\
Teacher Control & 1.67 & 4.00 & 3.14 & 0.43 & 0.74 \\
Principal Support of Teacher & 1.00 & 4.00 & 3.44 & 0.52 & 0.70 \\
Principal Support (first-year teacher) & 0.00 & 1.00 & 0.58 & 0.20 & 0.53 \\
Principal Context & & & & & \\
Pre-change occasions & 0.00 & 9.00 & 7.17 & 2.82 & \\
Post-change occasions & 0.00 & 10.00 & 2.37 & 2.27 & \\
School has 3 + 3 Occasions & 0.00 & 1.00 & 0.49 & 0.06 & \\
Years principal at this or any school & 0.00 & 33.00 & 5.96 & 5.58 & \\
Principal Practices - Leadership & & & & & \\
Instructional Breadth (minutes/week) & 120.00 & 1325.00 & 469.63 & 184.90 & \\
Instructional Depth (minutes/week) & 480.00 & 2020.00 & 1240.01 & 323.69 & \\
Parent Involvement & 1.00 & 4.00 & 2.85 & 0.64 & 0.78 \\
Principal Facilitation of Parent & 0.00 & 1.00 & 0.61 & 0.27 & 0.43 \\
Involvement & & & & & \\
Principal influence on Instructions & 1.33 & 4.00 & 3.52 & 0.51 & 0.64 \\
Decisions & 2.50 & 4.00 & 3.84 & 0.28 & 0.61 \\
Principal Autonomy & 0.00 & 1.00 & 0.65 & 0.48 & \\
Full Principal Autonomy & 166 & & & & \\
$N$ & & & &
\end{tabular}

Figure 1

Comparison of Sampled Schools to All California Eelmentary Schools

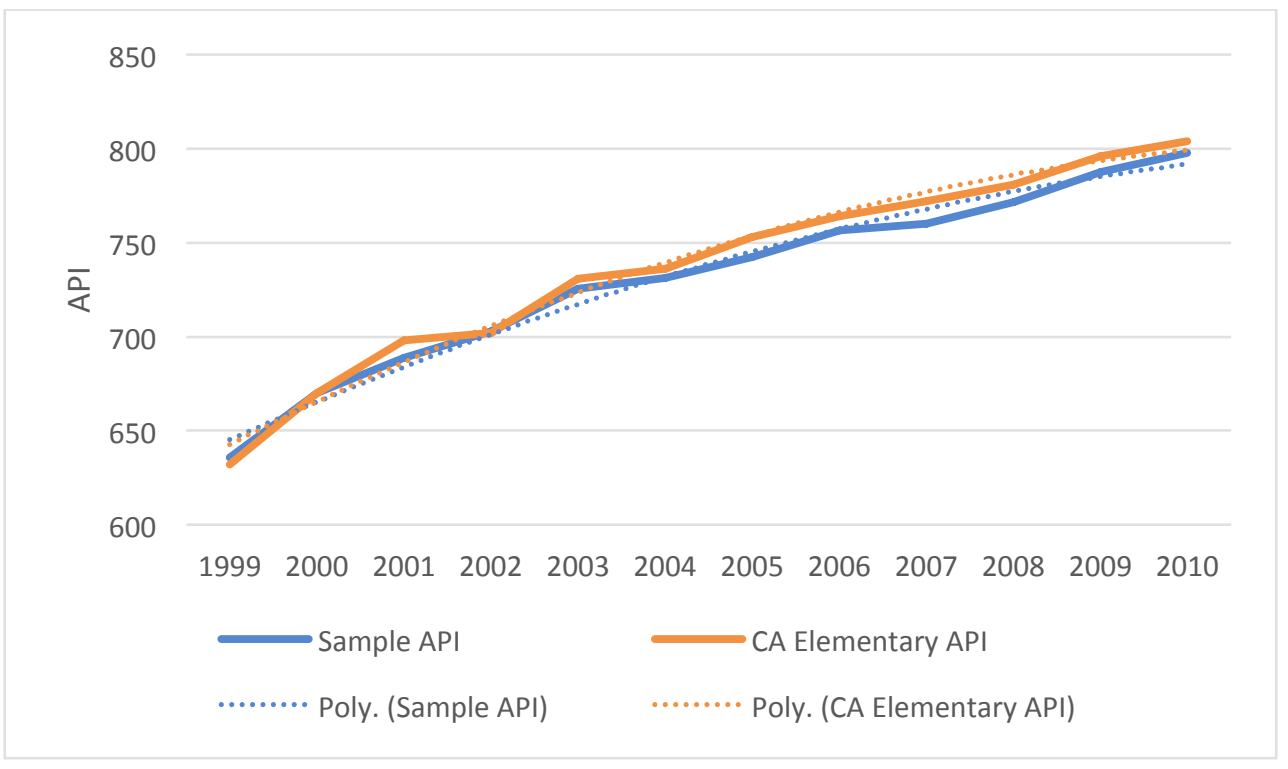




\section{Analysis Methods}

One method to generate causal claims, when random assignment is not feasible, is to apply a methodology that adequately accounts for other potential causes (Hallberg et al., 2018; Jacob et al., 2016; Kratochwill et al., 2010). This generally requires longitudinal data on principals and schools (Grissom et al., 2015), and few studies have had access to the data necessary to conduct such analyses. Recent studies that have had access to longitudinal data have estimated effects using difference in differences and some form of Interrupted Time Series (ITS) models to find effect sizes consistent with those reported in various meta-analyses (Branch, et al., 2012; Miller, 2013). Our analytic method is similar, although we utilized a mixed effects growth model (Raudenbush \& Bryk, 2002) as the basis for the ITS; this directly models progress as a function of time and importantly isolates between and within school residuals. An ITS model is a common approach to evaluating the impact of policy at various organizational (school) levels (Hallberg et al., 2018). The underlying premise is that the subjects are their own controls, and the key aspect is that the outcome preinterruption would remain unchanged (or have an unchanged trend) until an interruption occurs. The interruption to the school's trend in performance is the hiring of a new principal. The change in the school outcome and/or the change in the school outcome trend provides a test of the impact of a principal. Causal effects can be supported if common threats to internal validity can be addressed. History, or the occurrence of non-principal related cyclical or other events that might influence academic outcomes that coincide with the change in principals, is the greatest concern (Kratochwil et al., 2010). This is often addressed by including a comparison group that demonstrates where principals did not change the trend in performance remained the same. We included comparison principals in two ways: there are a small number of principals in our sample who never change schools; and, more importantly, over the span of the data, principals begin at a new school in different years so unlike examining the impact of a policy that begins at a specific date that might coincide with another event, our principal change date varies across the sample. Another threat to causal inferences is instrumentation, which is not a concern as we use the API as the outcome measure. Although ITS uses subjects as their own control, selection may still be a concern, but it was addressed in these data as they are a nationally represented stratified random sample of principals (Turkstan et al., 2007).

An important aspect of ITS is to accurately model the pre-interruption level and trend in the outcome. The potential outcome under control (pre interruption) is assumed to be the prediction for the year(s) of interest after a principal change and it is the deviation from the level and trend that generates the estimated effect (Shadish et al., 2002). The total number of occasions we utilized is consistent with previous studies employing similar approaches (Branch, et al., 2012; Miller, 2013) and is consistent with the recommendation of three pre- and three post-interruption data points (Bloom, 2003; Kratochwill et al., 2010). As depicted in Figure 1, API is increasing over the course of the data. The ITS model must accurately reflect this trend, which we model as:

$$
\mathrm{API}=\beta_{0 \mathrm{j}}+\beta_{1 \mathrm{j}} \mathrm{T}+\beta_{2 \mathrm{j}} \mathrm{T}^{2}+\beta_{3 \mathrm{j}} \mathrm{D}+\beta_{4 \mathrm{j}} \mathrm{P}+\beta_{5 \mathrm{j}} \mathrm{P}^{2}+e_{t}
$$

In equation (1), API is the Academic Performance Index at time $t$ for school $j$, T is the time in years, with 0 reflecting the last timepoint before a new principal begins ${ }^{5}, \mathrm{D}$ is an indicator variable for post intervention (coded 0 pre-intervention, and 1 post-intervention), $\mathrm{P}^{6}$ is the time since intervention (prior to intervention coded 0 , and post-intervention, continuous starting at 1 ), and et is the residual variation at time $t$ not explained by the model. The model incudes $\mathrm{T}^{2}$ and $\mathrm{P}^{2}$ terms that reflect the deceleration of growth in API over time. The effect of principals is estimated by the coefficients, $\beta_{3}$ (for year one change) and $\beta_{4}$, and $\beta_{5}$ for changes that persisted over time.

The extended model treats $\beta_{2}$ and $\beta_{3}$ as random effects and assumes they vary normally across schools. The aforementioned random effects are then modeled as a function of school context and principal practices (e.g., the constructs):

$$
\beta_{2 \mathrm{j}}=\gamma_{20}+\mathrm{C} \Gamma_{21}+\mathrm{P} \Phi_{22}+\mathrm{U}_{2}
$$

\footnotetext{
${ }^{5}$ This does not affect the estimate for principals because this estimate is within school, but it might affect the between principal variation of effects if years vary significantly in API variability. Auxiliary models included the year, and this did not substantively change any results.

${ }^{6}$ Often $\mathrm{P}$ is represented as $\mathrm{T} \times \mathrm{D}$.
} 


$$
\begin{aligned}
& \beta_{3 \mathrm{j}}=\gamma_{30}+\mathrm{C} \Gamma_{31}+\mathrm{P} \Phi_{32}+\mathrm{U}_{3} \\
& \beta_{4 \mathrm{j}}=\gamma_{40}+\mathrm{C} \Gamma_{41}+\mathrm{P} \Phi_{42}+\mathrm{U}_{4}
\end{aligned}
$$

The variable $\mathrm{C}$ represents a set of school context variables, $\mathrm{G}$ represents the estimated coefficients, $\mathrm{P}$ is a set of principal practices, and $\mathrm{F}$ represents the estimated coefficients. School context and principal variables are presented in Tables 1 and 2.

\section{RESULTS}

We present results that address the primary research question of whether there is significant impact of an elementary school principal on the trend in school academic achievement, as represented by the API. We also present results that address whether school context and principal leadership practices moderates the overall effect of principals. Table 2 presents the complete model providing causal estimates for principal effects. We further present results for both the complete data set and the $3+3$ Sample described above. The results in Table 2 indicated that the full sample and the $3+3$ sample results are substantively similar. We focus our presentation of results on the $3+3$ sample throughout. The results indicated that pre-interruption API was increasing each year (8.23 points/year) but doing so at a decelerating rate $(-1.48)$. The first-year effect of principals (principal change) was not statistically significant; the linear trend of principals was also not significant, but the quadratic effect $(1.28$ point/year) was significant $(p<.01)$. This implied a significant impact after the first year with an exponentially increasing impact over the next two to five years. The estimated effect sizes based on the results in Table 2 indicated that the effect size for a principal is 0.04 in year one, 0.11 in year two, 0.21 in year three, and up to 0.64 in year $\operatorname{six}^{7}$. The results are consistent with previous research (Branch, et al., 2012; Liebowitz \& Porter, 2019; Miller, 2013) and reflect the increasing effect associated with tenure. Within the API system, schools with an index score of 700, 600, and 500 would have been expected to demonstrate growth in (effect size) of $0.05,0.10$, and 0.14 , respectively.

Table 2 also presents the random (between school) effects. The results indicated there was considerable variation in both the principal change and the linear component of time after a principal change; the stand deviations are 16.1 and 8.6 for principal change and new principal time, respectively. These standard deviations indicated that the impact of a principal (initial change and linear trend) is substantively varied among schools. A 95\% confidence interval would range from about -30 to 34 API points. Table 2 also presents the log likelihood (-2LL), which we can use to compare model fit to a baseline model (not presented) that includes only an intercept and a linear slope. The statistically significant change in the log likelihood $(p<.01)$ indicated that this parametrization is a significant improvement over a baseline model.

The results of the model in Table 2 are graphically presented in Figure 2. The pre-trend indicated estimated school performance on the API over time without a principal change, while the post trend displayed the impact of the new principal on the API trend over time.

Table 3 presents the results when considering the moderating effect of school context ${ }^{8}$, both in terms of pre-and postprincipal change. The results in Table 3 indicated that both the percentage of students eligible for the National School Lunch Program (NSLP) and the percentage of students with IEPs negatively affect a school's API in the year immediately prior to principal change. Interestingly, these same two variables have a positive effect on the pre-principal change trend in API. With respect to the principal change and the trend in API post-change, NSLP negatively affects the post-change API trend. This implied that API annual linear growth in a school whose NSLP participation is one standard deviation above average (90\%) after a new principal begins would be about 4.95 API points lower than in a school with average NSLP participation (57\%). This implied that it takes an additional two years for a new principal to demonstrate positive API growth ${ }^{9}$.

\footnotetext{
${ }^{7}$ Effect size estimates in years 4, 5, 6 based on 61,49 , and 36 principals, respectively.

${ }^{8}$ School context variables are centered around their means, so the intercept and time coefficients represent the effects at a school with average NSLP, IEP, and ELs.

${ }^{9}$ From Table 3 the coefficient for Time/NSLP $=-0.15$. The $S D$ of NSLP is approximately 33 . The NSLP effect at $+1 S D=-0.15(33)$

$=-5$. The linear principal effect is 2.48 so the annual combined linear effect $=-2.5$. In year three of a principal's tenure the quadratic effect $=1.35^{*} 3^{\wedge} 2=12.2$, for a total trend effect of $-7.5+12.2=4.3$.
} 
Table 2

ITS Test of Principal Effects

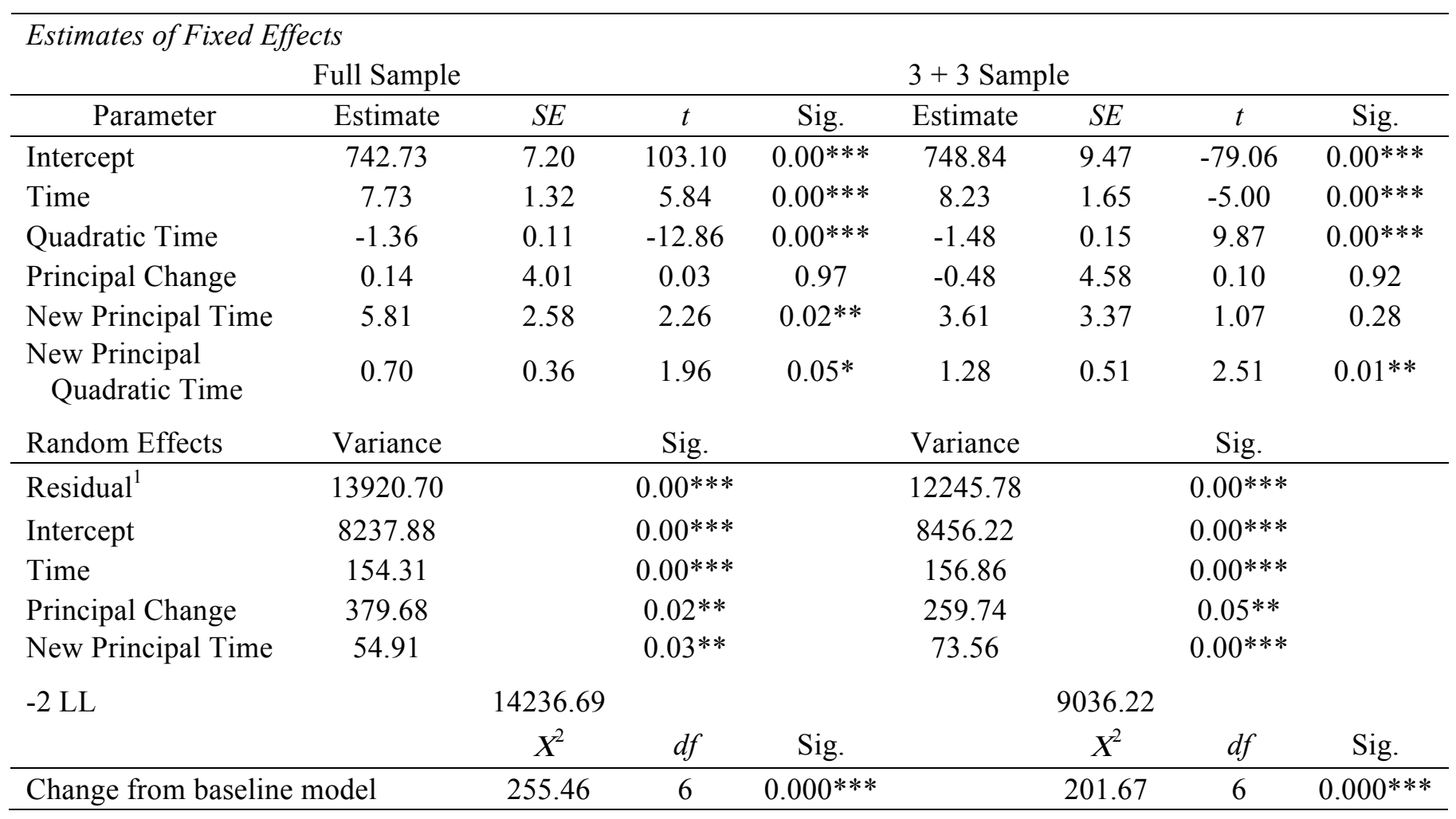

Figure 2

Principal Effect Over Time

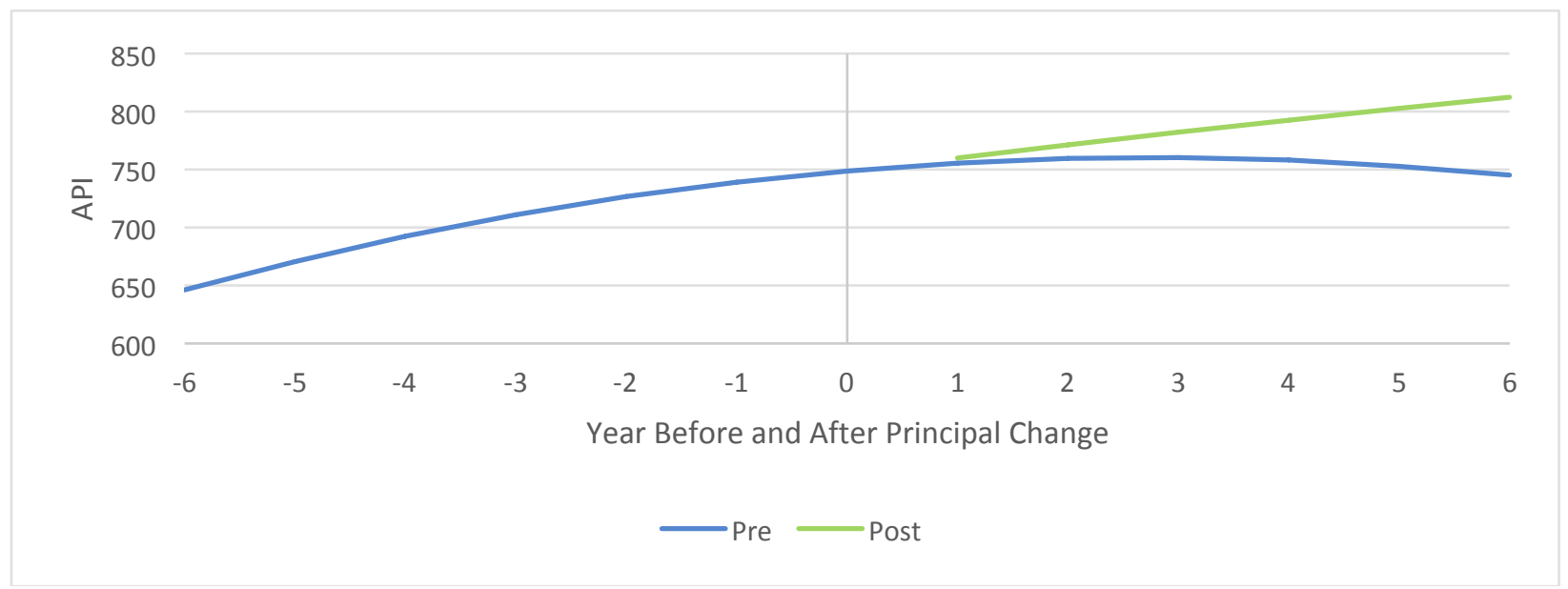


Table 3

Effect of School Context on Principal Effects

\begin{tabular}{|c|c|c|c|c|c|c|c|}
\hline \multirow{2}{*}{\multicolumn{5}{|c|}{ Estimates of Fixed Effects }} & \multicolumn{3}{|c|}{ Random Effects } \\
\hline & & & & & & & \\
\hline Parameter & Estimate & $S E$ & $t$ & Sig. & Variance & Sig. & $\begin{array}{c}\text { Reduction } \\
\%\end{array}$ \\
\hline Intercept & 739.12 & 7.31 & 101.13 & $0.00 * * *$ & 4205.10 & $0.00 * * *$ & 50.3 \\
\hline Percent NSLP & -1.63 & 0.24 & -6.87 & $0.00 * * *$ & & & \\
\hline Percent IEP & -0.80 & 0.33 & -2.45 & $0.02 * *$ & & & \\
\hline Percent EL & 0.10 & 0.55 & 0.19 & 0.85 & & & \\
\hline Time & 9.34 & 1.64 & 5.69 & $0.00 * * *$ & 116.93 & $0.00 * * *$ & 25.5 \\
\hline Percent NSLP & 0.14 & 0.04 & 3.34 & $0.00 * * *$ & & & \\
\hline Percent IEP & 0.13 & 0.06 & 2.31 & $0.02 * *$ & & & \\
\hline Percent EL & -0.12 & 0.10 & -1.24 & 0.22 & & & \\
\hline Quadratic Time & -1.44 & 0.16 & -8.78 & $0.00 * * *$ & & & \\
\hline Principal Change & -0.65 & 4.90 & -0.13 & 0.89 & 323.39 & $0.03 * *$ & 0.0 \\
\hline Percent NSLP & 0.01 & 0.12 & 0.09 & 0.93 & & & \\
\hline Percent IEP & -0.06 & 0.16 & -0.39 & 0.70 & & & \\
\hline Percent EL & 0.17 & 0.25 & 0.70 & 0.49 & & & \\
\hline New Principal Time & 2.48 & 3.44 & 0.72 & 0.47 & 57.84 & $0.05^{*}$ & 21.4 \\
\hline Percent NSLP & -0.15 & 0.05 & -3.04 & $0.00 * * *$ & & & \\
\hline Percent IEP & 0.04 & 0.07 & 0.62 & 0.54 & & & \\
\hline Percent EL & 0.10 & 0.10 & 1.00 & 0.32 & & & \\
\hline New Principal Quad Time & 1.35 & 0.51 & 2.63 & $0.01 * * *$ & & & \\
\hline \multirow[t]{2}{*}{$-2 \mathrm{LL}$} & & 7946.84 & & & & & \\
\hline & & $X^{2}$ & $d f$ & Sig. & & & \\
\hline Change from baseline model & & 1089.38 & 12 & $0.000 * * *$ & & & \\
\hline
\end{tabular}

In Table 4 below, we present results of the SASS-based principal leadership practices constructs. Ideally, we would add the SASS-based variables to the models presented in Table 3, but such a model does not converge, indicating potential parameterization issues. We addressed this by modeling only the post-change portion as this greatly reduces the number of fixed and random effects that are estimated ${ }^{10}$. Consistent with the emphasis of the $3+3$ Sample in the previous results, we included only principals who had at least three post occasions. The results for the contextual school variables were generally consistent with those presented in Table 3 . The results indicated that of the various practices included, only instructional breadth, parent involvement, and principal autonomy demonstrate some level of statistical significance. Instructional breadth had a negative impact on the API trend, which would seem logical given the API is a composite index of math and English language arts. Parent involvement reflected, to some extent, principal transformational practices. Principal autonomy, which captures salient features identified by Grissom et al. (2013), including teacher evaluation, hiring, and budget control, was marginally significant $(p<.10)$. Given that the principal autonomy variable is an indicator of whether the principal perceives having the full autonomy versus not having full autonomy, the effect of this variable is the difference between these sets of principals. Approximately $65 \%$ of principals believed they had full autonomy. Based on the results in Table 4, principals who perceived themselves as having full autonomy increased API growth by an annual effect size of about 0.04 greater than principals who do not perceive themselves as having full autonomy. As a set, the principal leadership constructs accounted for about $40 \%$ of the variation in post principal change in API growth.

\footnotetext{
${ }^{10}$ This eliminates the pre slope and quadratic slope as well as their random variance, covariances, covariances with the post slopes.
} 
Applying the ITS methodology and using a mixed effects growth model to test the impact of principals over time resulted in substantively meaningful effects of principals and importantly demonstrates the extent to which principal effects change over time. We also demonstrated that school context and leadership practices impact API growth over time.

Table 4

\section{Effect of School Context and Principal Leadership Practices on Principal Effects}

\begin{tabular}{lccccccc}
\hline $\begin{array}{l}\text { Estimates of Fixed } \\
\text { Effects }\end{array}$ & & & & & Random Effects & \\
\hline $3+3$ Sample & & & & & & \\
Parameter & Estimate & $S E$ & $t$ & Sig. & Variance & Sig. & $\begin{array}{c}\text { Reduction } \\
\%\end{array}$ \\
\hline Intercept & 746.06 & 7.47 & 99.84 & $0.00^{* * *}$ & 3539.36 & $0.00^{* * *}$ & 58.8 \\
$\quad$ Percent NSLP & -1.58 & 0.25 & -6.29 & $0.00^{* * *}$ & & & \\
Percent IEP & -1.06 & 0.32 & -3.37 & $0.00^{* * *}$ & & & \\
Percent EL & 0.88 & 0.43 & 2.05 & $0.04^{* *}$ & & & \\
Time & 9.49 & 2.93 & 3.24 & $0.00^{* * *}$ & 61.91 & $0.00^{* * *}$ & 40.4 \\
Percent NSLP & 0.16 & 0.06 & 2.70 & $0.01^{* * *}$ & & & \\
Percent IEP & 0.06 & 0.07 & 0.92 & 0.36 & & & \\
Percent EL & -0.21 & 0.08 & -2.74 & $0.01 * * *$ & & & \\
TC & -1.85 & 2.81 & -0.66 & 0.51 & & & \\
PST & 1.20 & 2.18 & 0.55 & 0.58 & & & \\
PSTYr1 & 2.01 & 2.96 & 0.68 & 0.50 & & & \\
Instructional Breadth & -0.02 & 0.01 & -2.60 & $0.01 * *$ & & & \\
Instructional Depth & 0.00 & 0.00 & -0.70 & 0.49 & & & \\
Parent Involvement & 8.90 & 2.04 & 4.36 & $0.00^{* * *}$ & & & \\
PFPI & -2.37 & 4.28 & -0.55 & 0.58 & & & \\
PIDM & 0.07 & 2.10 & 0.03 & 0.97 & & \\
Principal Autonomy & 3.77 & 2.05 & 1.84 & $0.07 *$ & & \\
Quadratic Time & -0.60 & 0.37 & -1.60 & 0.11 & & \\
-2 LL & & 2634.89 & & & & \\
\hline
\end{tabular}

\section{SUMMARY, IMPLICATIONS, AND RECOMMENDATIONS}

The purpose of our study was to add to the growing body of research providing causal evidence on the impact of principals on academic progress over time. We developed a unique dataset that afforded us an opportunity to not only generate causal estimates for elementary school principals but also examine leadership practices identified in the literature. The three key findings are that there are principal effects and these effects increase over time; that school context matters; and that principal autonomy is an important aspect of principals' impact on academic progress over time.

Substantively, the results are similar to recent research. Given the between-school variability in the first year of a new principal, we would expect $57 \%$ of schools changing principals to have a decrease in API, which is consistent with the findings of Miller (2013). By year three, however, we would expect $82 \%$ of schools to have exhibited improvement over their pre-change levels, which is consistent with the notion that it takes time for principal effects to manifest (Coelli \& Green, 2012). Our results also indicate that principals in schools with high at-risk populations (e.g., 90\% NSLP eligible) will need an additional two years to demonstrate API growth. The importance of principal autonomy reflects several facets related to teacher evaluation and feedback, is consistent with previous work (Grissom, Loeb, \& Master, 2013), and substantively impacts API annual growth with an effect size of 0.04 . These results have both implications and limitations, which we address next. 


\section{Implications and Limitations}

Statewide educational reform and school effectiveness has focused on standards, accountability, instruction, and curriculum. Our results provide additional empirical evidence about the importance of the school leader in implementing reform and advancing academic achievement. Under ESSA, school accountability considers multiple facets of schools, and much of the extant literature examines the impact of principals on non-academic outcomes (Liebowitz \& Porter, 2019). A subset of studies examines specific achievement outcomes, and this study highlights that principals directly impact metrics that are the basis for high-stakes accountability.

There are multiple implications of our results. One is that districts attempting to improve academic performance cannot expect school leaders to turn around schools in a single year, and school context influences a principal's ability to improve achievement growth over time. Specifically, schools with large at-risk populations are estimated to need an additional two years to demonstrate academic growth. Additionally, our results indicate that principal autonomy is an important aspect to consider and it increases annual progress. Autonomy may reflect the principal's ability to diagnose a school's unique problems noted as a key aspect of principal success (Day et al., 2016) or the ability to effectively provide feedback and guidance to teachers, which is not guaranteed simply because principals perform mandated evaluations (Goldschmidt \& Congdon, 2018). Importantly, a principal must maximize training to effectively diagnose, mentor, and include stakeholders to facilitate improvement. Previous research supports the inference that for this experience to substantively impact academic growth, it most accrue in the specific school that the principal is aiming to impact progress. Finally, our findings and the extent literature raise the question of whether district qualifying examinations for principals have been updated to reflect current salient, empirically-supported behaviors and practices that meaningfully impact school success.

The ITS methodology we employed provide rigorous estimates of principal effects and in theory affords an opportunity to examine school context and leadership practices; the complexity of this approach requires a larger dataset, and perhaps better articulated leadership constructs. This limitation can be addressed by continuing to link national and state datasets, where possible, in order to further the understanding of the mechanisms through which principals impact academic progress. Future research should continue to examine principal practices, and like this study, focus on progress over time, as short-term success is not a substitute for sustained improvement.

\section{REFERENCES}

Abu-Hussain, J. (2014). Leadership styles and value systems of school principals. American Journal of Educational Research, 2(12), 1267-1276. doi:10.12691/education-2-12-22.

Austin, W., Chen, B., Goldhaber, D., Hanushek, E., Holden, K., Koedel, C., Ladd, H., Luo, J., Parsons, E., Phelan, G., Rivkin, S., Sass, T., \& Turaeva, M. (2019). Path to the principalship and value added: A cross-state comparison of elementary and middle school principals, CALDER Working Paper No. 213-0119. https://caldercenter.org/publications/path-principalship-and-value-added-cross-state-comparison-elementary-andmiddle-school.

Goldschmidt, P. \& Congdon, A. (2018). Exploratory Analysis of Teacher Artifacts as Evidence of Educator Effectiveness Implementation Fidelity, Journal of School Administration Research and Development, 3(1), 6-18.

Bass, B. M. (1998). Transformational leadership: Industrial, military, and educational impact. Mahwah, NJ: Lawrence Erlbaum Associates.

Blank, R. K. (1986). Principal leadership in urban high schools: Analysis of variation in leadership characteristics. (ED269889). ERIC. https://eric.ed.gov/?id=ED269889

Bloom, H. S. (2003). Using "short" interrupted time-series analysis to measure the impacts of whole-school reforms: With applications to a study of accelerated schools. Evaluation Review, 27, 3-49.

Bottoms, G., \& O'Neill, K. (2001). Preparing a new breed of school principals: It's time for action. Atlanta, GA: Southern Regional Education Board.

Branch, G., Hanushek, E., \& Rivkin, S. (2012). Estimating the effect of leaders on public sector productivity: The case of school principals (NBER Working Paper No. 17803). National Bureau of Economic Research. doi:10.3386/w17803.

Burch, P. and Spillane, J. P. (2003). Elementary school leadership strategies and subject matter: reforming mathematics and literacy instruction. The Elementary School Journal, 103(5), 519-535.

Coelli, M. \& D. Green (2012). Leadership effects: School principals and student outcomes, Economics of Education Review, 31(1), 92-109. 
Cotton, K. (2003). Principals and student achievement: What the research says. Association for Supervision and Curriculum Development.

Day, C., Q. Gu, \& P. Sammons. (2016). The impact of leadership on student outcomes: How successful school leaders use transformational and instructional strategies to make a difference, Educational Administration Quarterly, 52(2), 221258. https://doi.org/10.1177/0013161X15616863

Dhuey, E. \& Smith, J. (2018). How school principals influence student learning. Empirical Economics, 54, 851-882.

Dutta, V. \& Sahney, S. (2016). School leadership and its impact on student achievement: The mediating role of school climate and teacher job satisfaction, International Journal of Educational Management, 30(6), 941-958.

Duke, D.L. (1987). School leadership and instructional improvement. Random House.

Dvir, T., Eden, D., Avolio, B. J., \& Shamir, B. (2002). Impact of trans- formational leadership on follower development and performance: A field experiment. Academy of Management Journal, 45, 735-744.

Grissom, J. A., Kalogrides, D., \& Loeb, S. (2015). Using student test scores to measure principal performance. Educational Evaluation and Policy Analysis, 37(1), 3-28.

Grissom, J. and Loeb, S. (2011) Triangulating principal effectiveness: How perspectives of parents, teachers, and assistant principals identify the central importance of managerial skills, American Educational Research Journal, 48(5), 10911123.

Grissom, J., Loeb, S. and Master, B. (2013). Effective instructional time use for school leaders: Longitudinal evidence from observations of principals, Educational Researcher, 42(8), 433-444.

Hallberg, K., Williams, R., Swanlund, A., \& Eno, J. (2018). Short comparative interrupted time series using aggregate school-level data in education research, Educational Researcher, 47(5): 295-306.

Hallinger, P. \& Murphy, J. (1985). Assessing the instructional management behavior of principals. The Elementary School Journal, 86(2), 217-247.DOI:10.1086/461445

Harris, Douglas N., Rutledge, S., Ingle, W.K., \& Thompson, C. (2006). When supply meets demand: Principal preferences and teacher hiring. [Paper presentation]. American Educational Research Association, San Francisco, CA.

Horng, E.L., Klasik, D., \& Loeb, S. (2010). Principal time-use and school effectiveness. American Journal of Education, 116, 491-523.https://doi.org/10.1086/653625

Jacob, B.A., \& Lefgren, L. (2005). Principals as agents: Subjective performance measurement in education. Working Paper \#11463. National Bureau of Economic Research. https://www.nber.org/papers/w11463

Jacob, R., Somers, M.A., Zhu, P., \& Bloom, H. (2016). The validity of the comparative interrupted time series design for evaluating the effect of school-level interventions. Evaluation Review, 40(3), 167-198. https://doi.org/10.1177/0193841X16663414

Knuth, R.K., \& Banks, P.A. (2006). The essential leadership model. NASSP Bulletin, 90(1), 4-18. https://doi.org/10.1177/0192636505283855

Liebowitz D.D., \& Porter L. (2019).The effect of principal behaviors on student, teacher, and school outcomes: A systematic review and meta-analysis of the empirical literature. Review of Educational Research, 89(5):785-827. DOI:10.3102/0034654319866133

Kratochwill, T., Hitchcock, J., Horner, R., Levin, J., Odom, S., Rindskopf, D., \& Shadish, W. (2010). Single-case designs technical documentation. Retrieved from What Works Clearinghouse website: http://ies.ed.gov/ncee/wwc/pdf/wwc scd.pdf

Mangin, M. (2007). Facilitating elementary principals' support for instructional teacher leadership. Educational Administration Quarterly, 43(3), 319-357.

Marks, H., \& Printy, S. (2003). Principal leadership and school performance: An integration of transformational and instructional leadership. Educational Administration Quarterly, 39, 370-397.

Marzano, R., Waters, T., \& McNulty, B. (2005). School leadership that works: From research to results. Association for Supervision and Curriculum Development.

Miller, A. (2013). Principal turnover and student achievement. Economics of Education Review, 36, 60-72.

Mulford B. \& Silins H. (2003). Leadership for organizational learning and improved student outcomes - what do we know? Cambridge Journal of Education, 33(2), 175-195.

Nir, E. \& Hameiri, L. (2014). School principals' leadership style and school outcomes: The mediating effect of powerbase utilization. Journal of Educational Administration, 52(2), 210-227. https://doi.org/10.1108/JEA-01-2013-0007 
Owings, W A., Kaplan, L.S., Nunnery, J., Marzano, R., Myran, S., \& Blackburn, D. (2006). Teacher quality and troops to teachers: A national study with implications for principals. NASSP Bulletin, 90(2), 102-131. https://doi.org/10.1177/0192636506289023

Raudenbush, S. \& Bryk, A. (2002). Hierarchical linear models: Applications and data analysis methods. 2nd ed. Sage Publications.

Robinson, V., Lloyd, C. \& Rowe, K. (2008). The impact of leadership on student outcomes: An analysis of the differential effects of leadership types. Educational Administration Quarterly, 44(5), 635-674.

Shadish, R., Cook, T., \& Campbell, D. (2002). Experimental and quasi-experimental designs for generalized causal inference. Houghton Mifflin.

Stein, M. \& Nelson, B. (2003). Leadership content knowledge. Educational Evaluation and Policy Analysis, 25(4), 423448.

Tickle, B.R., Chang, M., \& Kim, S. (2011). Administrative support and its mediating effect on U.S. public school teachers. Teaching and Teacher Education, 27, 342-349. doi:10.1016/j.tate.2010.09.002

Tourkin, S., Warner, T., Parmer, R., Cole, C., Jackson, B., Zukerberg, A., Cox, S., Soderborg, A. \& Gruber, K. (2007). Documentation for the 2003-04 Schools and Staffing Survey (NCES 2007-337). National Center for Education Statistics, U.S. Department of Education.

Waters, T., \& Kingston, S. (2005, September/October). The standards we need: A comparative analysis of performance standards shows us what is essential for principals to know and be able to do to improve achievement. Leadership, $35(1), 14$.

Waters, T., Marzano, R., \& McNulty, B. (2003). Balanced leadership: What 30 years of research tells us about the effect of leadership on student achievement. (ED481972). ERIC. https://eric.ed.gov/?id=ED481972

STEPHEN B. BLUESTEIN, EdD, is an education practitioner who has served as a principal and superintendent at the elementary school, middle school, high school, and continuation school levels. His research focuses on the effects school principal change has on student achievement at an institution, $\mathrm{He}$ is currently the Executive Director of Ivy Bound Academy of Math, Science, and Technology Charter Middle Schools, 15355 Morrison Street, Sherman Oaks, California 91403. Email: bluestein_ste@ivybnd.com

PETE GOLDSCHMIDT, PhD, is a professor in the Michael D. Eisner College of Education at California State University, Northridge. He teaches graduate courses in statistics, research methods, and program evaluation. His research focuses on using growth models to better inform stakeholders about student and school progress. He has previously served as the Assistant Secretary for Assessment and Accountability in the New Mexico Public Education Department. 